\title{
One Eye Sees, The Other Feels: Modalities for Fabrication of Custom-Made Ocular Prosthesis
}

\author{
Pramod K Chahar ${ }^{1}$, Abir Sarkar ${ }^{2}$, E Mahesh Gowda ${ }^{3}$, Poonam Prakash ${ }^{4}$, Vijaya Kumar R ${ }^{5}$, Prashant Awasthi ${ }^{6}$ \\ ${ }^{1}$ PG Resident, Department of Dental Surgery and Oral Health Sciences, ${ }^{2}$ PG Resident, Department of Dental Surgery and \\ Oral Health Sciences, ${ }^{3}$ Associate Professor, Department of Dental Surgery and Oral Health Sciences, ${ }^{4}$ Assistant Professor, \\ Department of Dental Surgery and Oral Health Sciences, ${ }^{5}$ Assistant Professor, Department of Dental Surgery and Oral Health \\ Sciences, ${ }^{6}$ Assistant Professor, Department of Dental Surgery and Oral Health Sciences, Armed Forces Medical College, Pune, \\ Maharashtra, India
}

Corresponding author: Pramod K Chahar, Department of Dental Surgery and Oral Health Sciences, Armed Forces Medical College, Pune, 411040, Maharashtra, India

DOI: http://dx.doi.org/10.21276/ijcmsr.2019.4.1.4

How to cite this article: Pramod K Chahar, Abir Sarkar, E Mahesh Gowda, Poonam Prakash, Vijaya Kumar R, Prashant Awasthi. One eye sees, the other feels: modalities for fabrication of custom-made ocular prosthesis. International Journal of Contemporary Medicine Surgery and Radiology. 2019;4(1):A15-A17.

\section{A B S T R A C T}

Introduction: The eye plays an important role in individual's personality. Loss of this organ severely damages not only the function of vision but also self-confidence. Rehabilitation of such defects with ocular prosthesis restores the form and esthetics. As iris placement is a technique sensitive procedure and also matching the iris color of contralateral healthy eye is a challenging task.

Case report: This case report describes prosthetic rehabilitation of ocular defect by custom made ocular prosthesis. Three different techniques used for the fabrication of iris of prosthetic eye are, iris from stock eye, painting of iris and digital iris to rehabilitate three different patients. These techniques resulted in accurate matching of iris of ocular prosthesis with patient's iris and enhanced the treatment outcome.

Conclusion: Ocular defect has a direct impact on individual's psychosocial well being. Custom made ocular prosthesis with accurately matching iris improves the quality of life of the patient.

Keywords: Custom Made Ocular Prosthesis, Iris Painting, Digital Iris, Stock Eye

\section{INTRODUCTION}

Eye is a vital organ for vision and is also a remarkable feature of individual's personality and appearance. Loss of an eye caused by trauma, tumour, infection, or congenital defects can cause an intense physical and psychological impact on one's personal, social, and professional life. ${ }^{1,2}$ There are various techniques/ treatment modalities to rehabilitate ocular defects either with stock or custom made prosthesis. The custom made ocular prosthesis have several advantages over stock ocular prosthesis like better adaptation in anopthalamic socket, improved cosmetic results, since there is control over the size and colour of iris and sclera and is comfortable to the patient, thus better acceptance. ${ }^{3,4}$ This article describes different clinical techniques for fabrication of custom ocular prosthesis.

\section{CASE REPORT}

Case: 1

A 28-year-old male patient was referred to the Dept of Prosthodontics with chief complaint of missing right eye due to a trauma 06 month back followed by loss of sight and shrinkage of globe. Patient was diagnosed as a case of Phthisis bulbi (Fig 1a). After thorough clinical examination, patient was taken up for rehabilitation with a custom-made ocular prosthesis with digital iris. Impression tray was fabricated by duplicating conformer in self cure acrylic resin (DPI self cure Acrylic resin, Bombay Burmah Trading Corporation, Mumbai) and hollow plastic handle was attached to inject impression material into the socket. Petroleum jelly was applied onto the eyelashes and impression was made by polyvinyl addition silicone light body consistency (Affinis, Krupp Vacudent Co. Germany). The patient was asked to carry out the eye movements to record the defect functionally. After removal, the impression was evaluated for any short comings. A two-piece master cast with indexing was prepared (Kalabhai ultrastone Type III, Kalabhai Karson Pvt Ltd, Mumbai) and a wax pattern was fabricated in white carving wax (Pyrex carving wax, Roorkee, india). The wax pattern was evaluated for contour with opening and closing movements after placing it in anopthalamic socket. The patient was instructed to keep his eyes fixed at one point, the centre of the pupil was measured with digital Vernier's calliper and transferred to the wax pattern. A digital photograph of the patient's iris was made with the help of fundus camera (Fig 1b). After adjustment of the colour and brightness of the photograph by software(Adobe photoshop), images of the remastered iris in 1:1 ratio (life-size) were printed on good- 


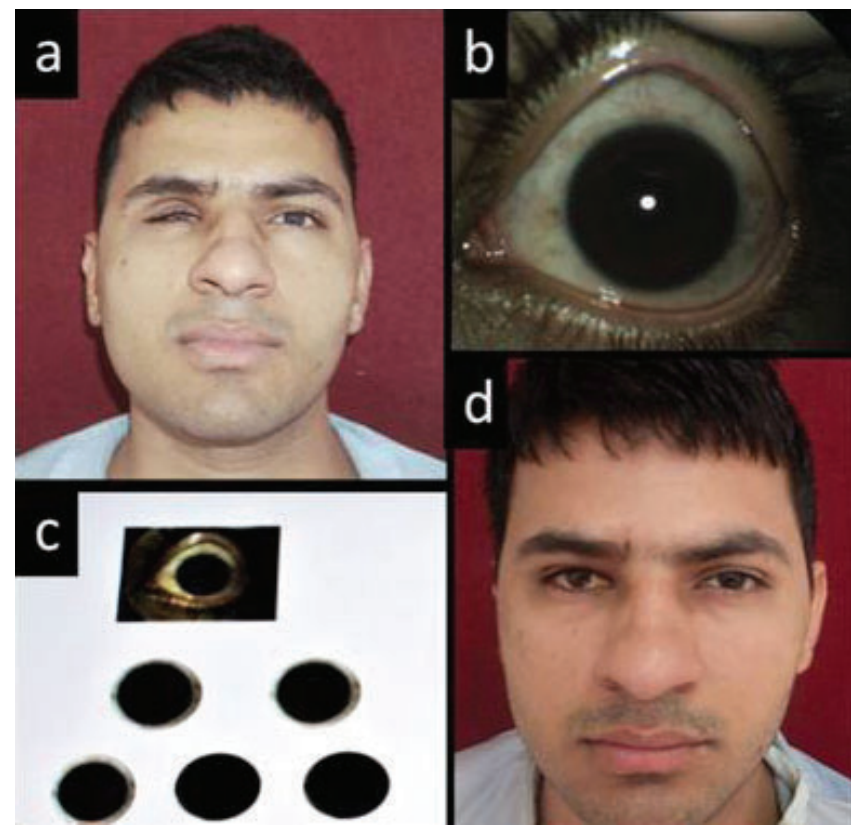

Figure-1: Patient with Pthisis bulbi rehabilitated with ocular prosthesis by digital iris technique. (a) Pre-op, (b) Photograph of iris by fundus camera (c) Printout of iris (d) Post -op (Prosthesis in situ)

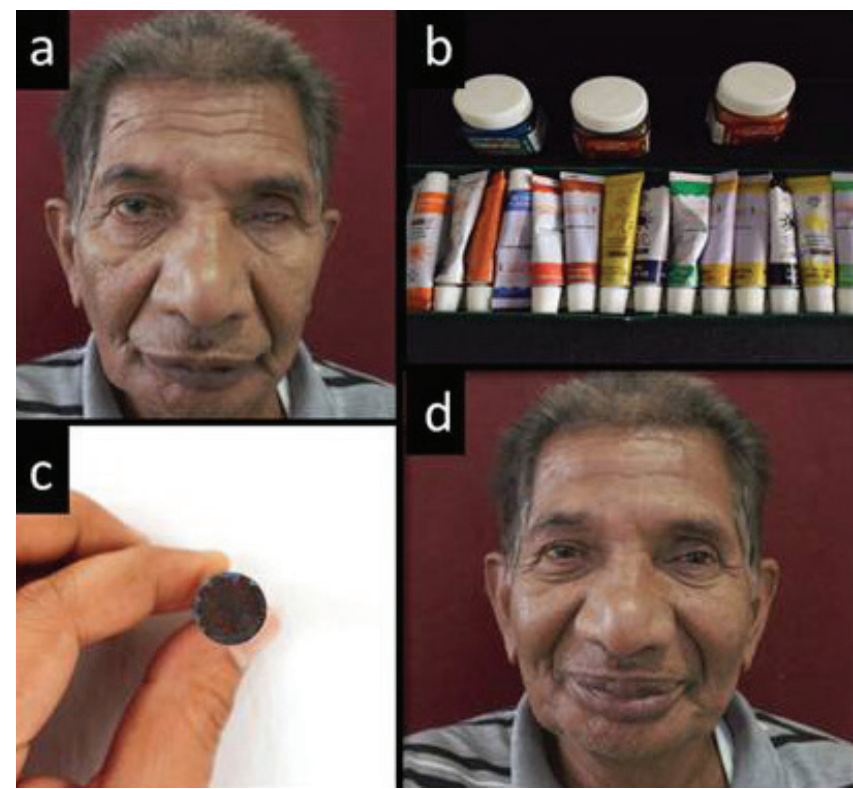

Figure-2: Patient with enucleated left eye rehabilitated by custom made ocular prosthesis with iris painting. (a) Preop (b) Acrylic colours (c) Painted Iris disc (d) Post -op (Prosthesis in situ)

quality photo-paper by using proprietary graphics software (Fig 1c). The iris was cut from the photo paper and attached to the corneal button and placed at predetermined position of pupil in wax pattern and tried in. After successful try-in and confirmation of position, prosthesis was flasked. Dewaxing was done, sclera colour was matched and the mould was packed with heat cure acrylic resin (DPI heat cure Acrylic resin, Bombay Burmah Trading Corporation, Mumbai). After processing and bench cooling prosthesis was retrieved, finished, and polished. To simulate veins of contralateral eye, rayon flocks were utilised. The mono-poly syrup (10 parts

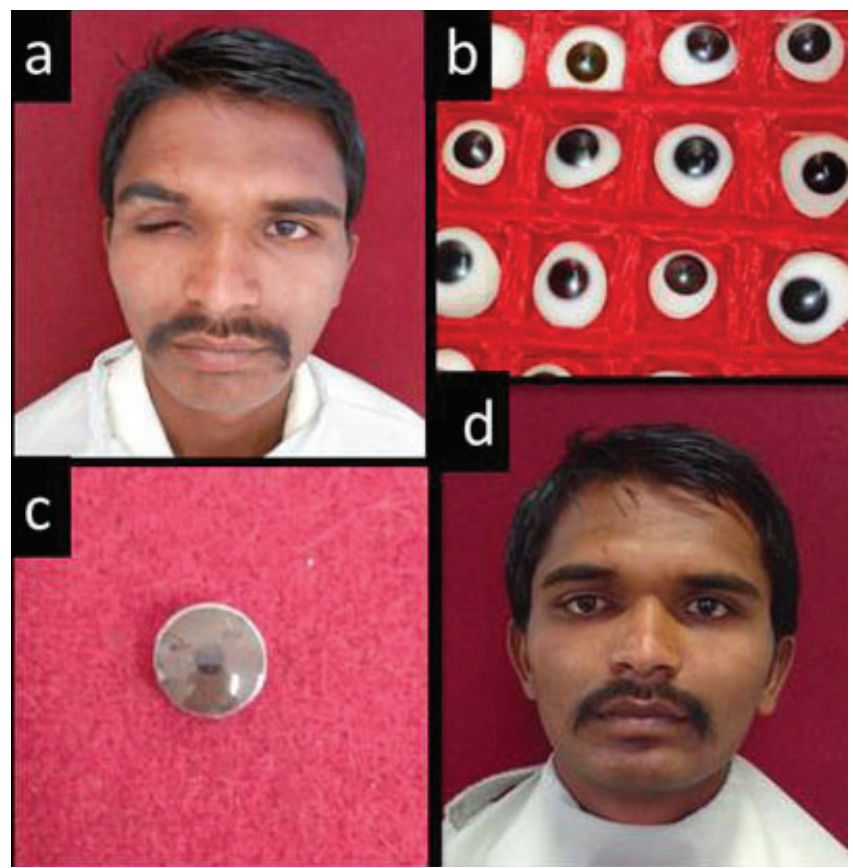

Figure-3: Patient with enucleated right eye rehabilitated by custom made ocular prosthesis using iris from stock eye. (a) Pre-op (b) Stock Eyes (c) Iris from stock eye (d) Post -op (Prosthesis in situ)

monomer: 1 part polymer) was used to simulate thin layer of clear conjunctiva and to give life like appearance. The final custom-made prosthesis was delivered to the patient (Fig 1d) and post insertion instructions were given.

Case: 2

A 62-year-old male patient was referred with residual ocular defect (Fig 2a) secondary to surgical management of choroidal melanoma treated 01 year back. The steps in the fabrication of wax pattern and marking position of pupil were same as for case 1 . A black iris disc of $1 \mathrm{~mm}$ smaller size (diameter) of iris of contralateral eye was selected and painted with acrylic paints (Fig 2b and 2c). After matching colour of painted iris disc with that of patient's iris, it was attached with corneal button by cyanoacrylate resin and embedded in wax pattern at previously marked position of pupil and tried in. The wax pattern and corneal button iris disc assembly was processed, and characterization was done similar to that for the case 1 . Finishing and polishing was done and prosthesis was delivered (Fig 2d). Post insertion instructions were given and patient was followed up for 6 months.

\section{Case: 3}

A 30-year-old male patient was referred to the department with residual ocular defect. Patient gave a history of RTA 2 year back in which he sustained penetrating injury to his right eye for which enucleation was carried out. (Fig 3a). After surgery, eye conformer was placed to maintain the space for prosthesis and prevent shrinkage. Local examination of anopthalamic socket was done and patient was taken up for rehabilitation with custom made ocular prosthesis. All steps for fabrication of prosthesis were followed like previous cases, except for selection of iris. After wax pattern try in, iris of similar size and colour was selected from stock eye, removed and placed in wax pattern, try in was done 
to confirm position of iris and pupil Fig $3 b$ and 3c). After minor adjustments, prosthesis was processed. After finishing, polishing and characterisation, prosthesis was inserted (Fig $3 \mathrm{~d})$ and post insertion instructions were given.

\section{DISCUSSION}

Impression procedures of residual ocular defect play a very crucial role for accurate adaptation of custom made ocular prosthesis and for comfort of the patient. Impression can be made with perforated custom made self cure acrylic impression tray or by using an eye conformer to record proper extension of the anopthalamic socket. Functional movements of eyes are carried out to record the underlying tissue for proper fit of prosthesis and to simulate the movements of contralateral healthy eye. Various impression materials have been used to make the impression of socket. Most commonly used are neutral $\mathrm{pH}$ alginate and polyvinyl addition silicone with light body consistency. In this case series also, impressions were made with light body addition silicone as the material is dimensionally stable impression and is non- irritating to underlying conjunctiva.

The selection, fabrication and positioning of the prosthetic iris is an important, challenging, and critical step during the fabrication of custom ocular prosthesis. ${ }^{5}$ Several variations exist in the fabrication technique of prosthetic iris either by painting, taking iris from stock eye or replicating iris by digital technology. The digital photographic iris fabrication produces good aesthetic results because it replicates the patient's iris with minimal colour modifications and simpler compared to the conventional method of hand painting. ${ }^{6}$ The described technique is practical and less time-consuming method of making custom-made ocular prosthesis with minimal artistic skills. However, it presents challenges of macro photography and preventing image of flash or camera in the Iris. The second technique of iris painting requires skill and patience to paint and simulate colour of natural iris. It is a time consuming and technique sensitive procedure but if followed diligently excellent aesthetic results can be achieved. The third technique of acquiring iris from stock eye is simple straightforward method to fabricate custom ocular prosthesis in limited time period while still achieving good results.

\section{CONCLUSION}

An accurate iris reproduction is fundamental for the best aesthetic results in patients with an ocular defect. Custommade ocular prosthesis gives better aesthetic and functional results in comparison to stock prosthesis. To prevent potential problems that may arise with long-term use of the custommade prosthesis, further follow-up is necessary to check the condition of the ocular prosthesis and further adjustments deemed necessary.

\section{REFERENCES}

1. Taylor TD. Clinical and maxillofacial prosthetics, quintessence publishing: Berlin; 2000;265-76.

2. Bartlett SO, Moore DJ. Ocular prosthesis: A physiologic system. Journal of Prosthetic Dentistry. 1973;29(4):4509.
3. Kaur A, Pavaiya A, Singh SV, Singh RD, Chand P. A simplified approach to fabrication of an ocular prosthesis: A case series. Indian Journal of Dental Research. 2010;21(4):615

4. Cevik P, Dilber E, Eraslan O. Different techniques in fabrication of ocular prosthesis. Journal of Craniofacial Surgery. 2012;23(6):1779-81

5. Raizada K, Rani D. Ocular prosthesis. Cont Lens Anterior Eye 2007;30(6):152-162

6. Naveen HC,Porwal A, Nelogi S.Prosthetic rehabilitation of phthisis bulbi by digital imaging technique:a case report. Cont Lens Anterior Eye 2010;33(3):231-234.

Source of Support: Nil; Conflict of Interest: None

Submitted: 15-12-2018; Accepted: 19-12-2019; Published online: 31-01-2019 